\title{
Carbon isotopic study from Khajjiar Lake sediments, Himachal Pradesh, India.
}

\section{MS. NEHA KHOLIA, M.SC. AND BAHADUR SINGH} KOTLIA

Kumaun University

Presenting Author: neha.kholia93@gmail.com

A sediment core of $765 \mathrm{~cm}$ in length was recovered by the livingstone corer from the Khajjiar Lake, NW Himalaya. The saucer shaped Khajjiar Lake $\left(32^{\circ} 32^{\prime} \mathrm{N}\right.$ and $\left.76^{\circ} 03^{\prime} \mathrm{E}\right)$ is located about $1920 \mathrm{~m}$ above sea level in the western part of Chamba district of Himachal Pradesh. The sediments of the lake show the dominance of silt component followed by sand and clay. Based on the sedimentological parameters sandy silt, silt and mud facies have been identified. The sediments from the lake have been analyzed in order to depict the isotopic and organic compositions. Stable isotopes in lake basins are sensitive to changes in effective precipitation. The results obtained shows that the $8^{13} \mathrm{C}$ values ranging from -32.9 to $-20.2 \%$ with the average of $-27.9 \%$, which suggest the dominance of $\mathrm{C} 3$ plant species. The values of TOC ranges from 0.9 to $31.2 \%$ (average of $11.5 \%$ ) suggest the decrease in the detrital input in the lake sediments and flourishing vegetation in the catchment area. 